\title{
Synthesis and magnetic properties of cobalt ferrite nanoparticles formed under hydro and solvothermal conditions
}

\author{
B. V. Vasil'ev ${ }^{1,2}$, R. Yu. Smyslov ${ }^{1}$, D. A. Kirilenko ${ }^{3,4}$, A. N. Bugrov ${ }^{1,2}$ \\ ${ }^{1}$ Institute of Macromolecular Compounds RAS, Bolshoy pr. 31, 199004 Saint Petersburg, Russia \\ ${ }^{2}$ Saint Petersburg Electrotechnical University “LETI”, ul. Professora Popova 5, \\ 197376 Saint Petersburg, Russia \\ ${ }^{3}$ Ioffe Institute RAS, Politekhnicheskaya ul. 26, 194021 Saint Petersburg, Russia \\ ${ }^{4}$ ITMO University, Kronverskii avenue 49, 197101 Saint Petersburg, Russia \\ boris8152@gmail.com,urs@macro.ru,demid.kirilenko@mail.ioffe.ru, alexander.n.bugrov@gmail.com
}

PACS 75.20.-g; 75.75.+a

DOI 10.17586/2220-8054-2021-12-4-492-504

\begin{abstract}
Cobalt ferrite nanoparticles were synthesized both in hydro and in solvothermal conditions from Co and Fe salts of different chemical nature (nitrates and chlorides) taken in a 1:2 cation ratio. Varying the chemical prehistory, synthesis temperature, isothermal holding time, and the reaction medium composition made it possible to obtain a set of $\mathrm{Co}_{x} \mathrm{Fe}_{3-x} \mathrm{O}_{4}$ nanoparticles of different average diameters and isomorphic substitution degree $x$. The resulting nanoparticles' elemental composition, crystal structure, sizes, and magnetic properties were determined using EDX analysis, X-ray diffraction, transmission electron microscopy, and SQUID magnetometry. The temperature dependences of the coercivity, remanent magnetization, squareness on both the average diameter and the stoichiometry of nanoparticles are considered. $\mathrm{Co}_{x} \mathrm{Fe}_{3-x} \mathrm{O}_{4}$ nanocrystals ranged from 11 to $29 \mathrm{~nm}$ were single magnetic domains and showed ferrimagnetic behavior at room temperature. The hardest magnetic nanoparticles with maximum squareness values in the high-temperature region were formed with $x=0.79$ using solvothermal treatment of cobalt and iron nitrates at $250{ }^{\circ} \mathrm{C}$, 7 MPa for 10 hours.
\end{abstract}

Keywords: single-domain cobalt ferrite, ferrimagnetic nanocrystals, size-controlled synthesis, stoichiometry, Rietveld refinement, coercive field, saturation magnetization, squareness.

Received: 19 October 2020

Revised: 9 August 2021

\section{Introduction}

Cobalt ferrite is well known as a hard magnetic material with a high coercive force $(11.9 \mathrm{kOe})$ [1], moderate saturation magnetization $(85 \mathrm{emu} / \mathrm{g})$ [2], strong magnetocrystalline anisotropy $\left(2.7 \times 10^{6} \mathrm{~J} / \mathrm{m}\right)$, and high Curie temperature $\left(520^{\circ} \mathrm{C}\right)[3]$, which are combined with its increased mechanical hardness and chemical stability. This opens up opportunities for the potential use of $\mathrm{CoFe}_{2} \mathrm{O}_{4}$ in high-frequency applications [4], microwave devices [5], highdensity magnetic storage materials [6], ferrofluids [7], as well as functional systems for hyperthermia [8], targeted drug delivery, and MRI diagnostics [9].

$\mathrm{CoFe}_{2} \mathrm{O}_{4}$ belongs to the single-phase structure of a cubic reverse spinel with the Fd-3m space group, where one half of $\mathrm{Fe}^{3+}$ ions occupies tetrahedral vacancies (A-position), and the other populates octahedral interstices (Bposition) along with $\mathrm{Co}^{2+}[10,11]$. In the case of cobalt ferrite nanoparticles, there is also a mixed spinel structure with the $\left(\mathrm{Co}_{z}^{2+} \mathrm{Fe}_{1-z}^{3+}\right)^{A}\left[\mathrm{Fe}_{1+z}^{3+} \mathrm{Co}_{1-z}^{2+}\right]^{B} \mathrm{O}_{4}$ formula, where $z$ is the inversion degree of the corresponding metal ions $[3,12]$. A change in $x$ values of $\mathrm{Co}_{x} \mathrm{Fe}_{3-x} \mathrm{O}_{4}$ particles strongly affects their magnetic properties since properties largely depend on the superexchange interaction between the tetrahedral and octahedral sublattices [3, 10, 13, 14]. So, for dispersions of cobalt ferrite nanoparticles obtained by the $\mathrm{pH}$-controlled coprecipitation method, the coercive force $\left(\mathrm{H}_{c}\right)$ did not change monotonically depending on the stoichiometry. At first, $\mathrm{H}_{c}$ decreased up to the substitution degree of 0.2 , then increased in the range $x=0.2-0.6$, after which it again decreased at a higher concentration of $\mathrm{Co}^{2+}(x=0.8)$. The saturation magnetization $\left(\mathrm{M}_{s}\right)$, on the contrary, increased to $x=0.2$ and, having reached its maximum value of $61.78 \mathrm{emu} / \mathrm{g}$, decreased with a further increase in the concentration of divalent cobalt in the spinel structure [3]. The coprecipitation method presented in another work [13] made it possible to obtain cobalt ferrite nanoparticles for which an increase in $x$ from 0 to 1 promoted growth in $\mathrm{H}_{c}$ from 7.75 to 340.5 Oe and a decrease in $\mathrm{M}_{s}$ from 59.1 to $32.7 \mathrm{emu} / \mathrm{g}$ at room temperature. For $\mathrm{Co}_{x} \mathrm{Fe}_{3-x} \mathrm{O}_{4}$ particles synthesized by thermal decomposition of precursors, starting with an substitution degree of 0.1 and ending with 0.7 , the authors of [14] recorded an increase in the coercivity from 120 to $610 \mathrm{Oe}$, after which it began to decrease down to 325 Oe at $x=1.5$. In turn, the $\mathrm{M}_{s}$ of these nanoparticles decreased as their composition approached stoichiometric since $\mathrm{Co}^{2+}$ has a lower magnetic moment than $\mathrm{Fe}^{3+}$. In [10], during the formation of cobalt ferrite nanocrystals under hydrothermal conditions, a 
similar tendency was observed in the variation of $\mathrm{M}_{s}$ and $\mathrm{H}_{c}$, but the maximum value for the latter was reached at $x=0.75$ and was 810 Oe. Thus, the substitution degree of $\mathrm{Fe}^{3+}$ by $\mathrm{Co}^{2+}$ in octahedral positions and the conditions of formation of cobalt ferrite nanoparticles affect their final magnetic characteristics.

In addition, to precise control of the composition and structure of $\mathrm{CoFe}_{2} \mathrm{O}_{4}$, practical applications require the ability to regulate particle size at the nanoscale. It is known that fine tuning the size of cobalt ferrite nanocrystals in the single magnetic domain region can achieve extremely high values of the coercive force at room temperature [1,15]. With an increase in the particle diameter, both the saturation magnetization and the coercive force rapidly accrue, but upon transition to the multidomain state, $\mathrm{M}_{s}$ reaches a plateau with a characteristic value of bulk $\mathrm{CoFe}_{2} \mathrm{O}_{4}$, and $\mathrm{H}_{c}$ passes through a maximum. Depending on the synthesis conditions, the critical size $\left(\mathrm{D}_{c r}\right)$ of $\mathrm{CoFe}_{2} \mathrm{O}_{4}$ nanoparticles corresponding to the boundary of the single-domain region varies from 5 to $40 \mathrm{~nm}$ [14, 16-22]. For cobalt ferrite nanoparticles synthesized by the forced hydrolysis in polyol, $\mathrm{D}_{c r}$ was about $5 \mathrm{~nm}$ with a maximum coercivity of $14.5 \mathrm{kOe}(5 \mathrm{~K})$ and a saturation magnetization of $85 \mathrm{emu} / \mathrm{g}(5 \mathrm{~K})$ [16]. The micellar microemulsion method [17] made it possible to obtain the maximum value of $\mathrm{H}_{c}(16 \mathrm{kOe})$ and provided a plateau for $\mathrm{M}_{s}(70 \mathrm{emu} / \mathrm{g})$ at a particle size of $10 \mathrm{~nm}$. In the case of approaches associated with thermal decomposition of precursors [14] and high temperature non-hydrolysis process combined with seed-mediated growth [18], the critical size was $12 \mathrm{~nm}$ with magnetic characteristics of $22.8 \mathrm{kOe}, 69 \mathrm{emu} / \mathrm{g}(2 \mathrm{~K})$, and $18 \mathrm{kOe}, 82 \mathrm{emu} / \mathrm{g}(5 \mathrm{~K})$, respectively. Larger $\mathrm{D}_{c r}$ were recorded for $\mathrm{CoFe}_{2} \mathrm{O}_{4}$ nanoparticles obtained by coprecipitation of cobalt and iron salts in the presence of oleic acid (28 nm) [19], hydrothermal synthesis with annealing $(40 \mathrm{~nm})$ [20], and the polymeric method via a thermal decomposition process $(40 \mathrm{~nm})$ [21]. A special place among the above methods is occupied by hydro(solvo)thermal synthesis due to relatively mild temperature conditions, the possibility of effective control of the composition, size, and morphology of the resulting nanoparticles, as well as due to the high purity and homogeneity degree of the resulting products [23-26].

Therefore, the main task of this work was to determine the effect of the nature of precursors, the composition of the reaction medium, the temperature and time of isothermal holding on the size, structure, and magnetic properties of cobalt ferrite nanoparticles formed under hydro(solvo)thermal conditions.

\section{Experimental part}

\subsection{Synthesis of cobalt ferrite nanoparticles under hydrothermal conditions}

$\mathrm{Co}_{x} \mathrm{Fe}_{3-x} \mathrm{O}_{4}$ nanoparticles were obtained by coprecipitation of cobalt and iron hydroxides from aqueous solutions of their chlorides or nitrates, followed by dehydration under hydrothermal conditions. Based on the analysis of published data, the following procedure for synthesizing cobalt ferrite nanoparticles was developed.

Prepared solutions of $\mathrm{Co}\left(\mathrm{NO}_{3}\right)_{2} \cdot 6 \mathrm{H}_{2} \mathrm{O}$ (analytically pure, GOST 4328-77, Vecton, Russia) and $\mathrm{Fe}\left(\mathrm{NO}_{3}\right)_{3} \cdot 9 \mathrm{H}_{2} \mathrm{O}$ (chemically pure, CAS 10294-41-4, Vekton, Russia) or $\mathrm{CoCl}_{2} \cdot 6 \mathrm{H}_{2} \mathrm{O}$ (analytically pure, GOST 4328-77, Vecton, Russia) and $\mathrm{FeCl}_{3} \cdot 9 \mathrm{H}_{2} \mathrm{O}$ (chemically pure, CAS 10294-41-4, Vekton, Russia) were mixed for 2 hours. Then an aqueous solution of ammonia $\left(\mathrm{NH}_{4} \mathrm{OH}\right)$ was added dropwise in an amount of $10 \mathrm{ml}$. The precipitate had formed at $\mathrm{pH}=10$, it was repeatedly washed with distilled water until a negative reaction for chloride or nitrate ions and dried at $65{ }^{\circ} \mathrm{C}$ to constant weight. After cooling to room temperature, the resulting powder was crushed and transferred in an amount of $0.5 \mathrm{~g}$ to an autoclave with a teflon cell. $14.5 \mathrm{ml}$ of distilled water was added to a weighed portion of a mixture of cobalt and iron hydroxides, and hydrothermal treatment was carried out. The holding time of the reaction mixture in the autoclave was 10 hours at a temperature of $200{ }^{\circ} \mathrm{C}$ and pressure of $7 \mathrm{MPa}$. Further, for nanoparticles of cobalt ferrite obtained from chlorides and nitrates under hydrothermal conditions, the abbreviations HC200 and HN200 will be used, respectively.

\subsection{Synthesis of cobalt ferrite nanoparticles under solvothermal conditions}

$\mathrm{Co}\left(\mathrm{NO}_{3}\right)_{2} \cdot 6 \mathrm{H}_{2} \mathrm{O}$ and $\mathrm{Fe}\left(\mathrm{NO}_{3}\right)_{3} \cdot 9 \mathrm{H}_{2} \mathrm{O}$ were each dissolved separately in $15 \mathrm{ml}$ of ethylene glycol $\left(\mathrm{C}_{2} \mathrm{H}_{6} \mathrm{O}_{2}\right)$ and, after complete dissolution, were mixed. Then, $3.8 \mathrm{ml}$ of ammonia in the form of a $25 \%$ aqueous solution as a precipitant $(\mathrm{pH}=10)$ were added and mechanically stirred for 1 hour. The resulting mixture was placed in an autoclave and kept for 5 hours at $250{ }^{\circ} \mathrm{C}$ or 10 hours at $100-250{ }^{\circ} \mathrm{C}$, where the step was taken equal to $50{ }^{\circ} \mathrm{C}$. The pressure in the reaction vessel during the synthesis was $7 \mathrm{MPa}$. After cooling to room temperature, the resulting black powder was centrifuged for 10 minutes at $8000 \mathrm{rpm}$. The precipitate of nanoparticles washed with alcohol was dried in air at $45^{\circ} \mathrm{C}$. Subsequently, for brevity, these samples will be designated as SN100, SN150, SN200, SN250 ${ }^{5}$, and SN250 10 , where the number in the title block indicates the temperature, and the superscript indicates the synthesis time.

Using $\mathrm{CoCl}_{2} \cdot 6 \mathrm{H}_{2} \mathrm{O}$ and $\mathrm{FeCl}_{3} \cdot 9 \mathrm{H}_{2} \mathrm{O}$ to form cobalt ferrite nanoparticles under solvothermal conditions, the synthesis procedure was identical to that described above, and the name of the sample was taken as SC250. 
TABLE 1. Parameters of the $\mathrm{CoFe}_{2} \mathrm{O}_{4}$ phase with a cubic cell $\alpha=\gamma=\beta=90^{\circ}$

\begin{tabular}{|c|c|c|}
\hline \multirow{2}{*}{ Sample } & Unit cell parameters & Crystalline domain \\
\cline { 2 - 3 } & $a=b=c, \AA$ & $D, \mathrm{~nm}$ \\
\hline HC200 & $8.3809 \pm 0.0008$ & $13.9 \pm 0.5$ \\
\hline HN200 & $8.3832 \pm 0.0009$ & $11.9 \pm 0.5$ \\
\hline SC250 $^{2}$ & $8.3965 \pm 0.0005$ & $28.7 \pm 0.5$ \\
\hline SN250 $^{10}$ & $8.3992 \pm 0.0008$ & $24.8 \pm 0.5$ \\
\hline SN250 $^{5}$ & $8.3974 \pm 0.0008$ & $15.5 \pm 0.5$ \\
\hline SN200 & $8.4015 \pm 0.0006$ & $16.7 \pm 0.5$ \\
\hline SN150 & $8.4176 \pm 0.0012$ & $12.2 \pm 0.5$ \\
\hline SN100 & - & - \\
\hline
\end{tabular}

\subsection{Instruments and characterization}

The size and shape of the cobalt ferrite nanoparticles obtained in this study were determined using a Jeol JEM2100F transmission electron microscope at an accelerating voltage of $200 \mathrm{kV}$. Aqueous dispersions of $\mathrm{CoFe}_{2} \mathrm{O}_{4}$ nanopowders were deposited onto copper grids covered with graphene paper to obtain bright-field images.

X-ray diffraction (XRD) patterns of $\mathrm{CoFe}_{2} \mathrm{O}_{4}$ nanoparticles were obtained using a Rigaku SmartLab diffractometer with $\operatorname{CoK} \alpha$ radiation. The survey was carried out in the $2 \theta$ range of angles from 5 to $90^{\circ}$ with a scanning speed of $0.5^{\circ} / \mathrm{min}$. The structure analysis of the obtained XRD patterns was carried out in the MAUD program [27] using the Rietveld method.

Energy dispersive X-ray (EDX) analysis was carried out to investigate the elemental composition of the obtained cobalt ferrite nanoparticles. EDX analysis was carried out on a TESCAN VEGA 3 SBH scanning electron microscope (TESCAN BRNO, Czech Republic) with an Advanced Aztec Energy energy-dispersive attachment for elemental microanalysis based on an X-act semiconductor energy dispersive detector (Oxford Instruments NanoAnalysis, Great Britain).

The study of the magnetic properties of the synthesized cobalt ferrite nanoparticles was carried out on a superconducting quantum interferometer (SQUID) MPMS SQUID VSM (Quantum Design) with a magnetic field up to $7 \mathrm{~T}$.

\section{Results and discussion}

Qualitative X-ray phase analysis of nanoparticles obtained from salts (nitrates, chlorides) of cobalt and iron under hydro- and solvothermal conditions was carried out using the PDWin 4.0 software package (Burevestnik, Russia). Its results showed that $\mathrm{HC} 200, \mathrm{HN} 200, \mathrm{SN} 150, \mathrm{SN} 200, \mathrm{SN} 250^{5}, \mathrm{SN} 250^{10}$ and SC250 samples correspond to the crystal structure of $\mathrm{CoFe}_{2} \mathrm{O}_{4}$ (PDF card No. 3-864). No supplementary impurity phases were found during the analysis, except for the SN100 and SN150 nanoparticles. In their XRD patterns, in addition to the amorphous halo and peaks of partially crystallized cobalt ferrite in the $2 \theta$ region of $8^{\circ}$, a reflection corresponding to the double layered hydroxide (Co-Fe LDH) [28] was observed. This phase, passed into $\mathrm{CoFe}_{2} \mathrm{O}_{4}$ when the synthesis temperature increased to $200{ }^{\circ} \mathrm{C}$ and higher (Fig. 1a,b,c). Analysis of powder XRD data (Fig. 1) using the Rietveld method made it possible to track the simultaneous changes in crystallite sizes and unit cell parameters (Table 1). For nanoparticles formed from cobalt and iron nitrates under solvothermal conditions, the crystallite size grew with an increase in the synthesis temperature, while the volume of a cubic unit cell, on the contrary, decreased. A longer isothermal holding of the reaction mixture also promoted an increase in the size of the $\mathrm{Co}_{x} \mathrm{Fe}_{3-x} \mathrm{O}_{4}$ crystallites, but at the same time, had little effect on the unit cell parameters. The use of $\mathrm{CoCl}_{2} \cdot 6 \mathrm{H}_{2} \mathrm{O}$ and $\mathrm{FeCl}_{3} \cdot 9 \mathrm{H}_{2} \mathrm{O}$ as precursors for the synthesis of nanoparticles led to the compaction of the cubic unit cell and the formation of larger coherent scattering regions in comparison with the samples obtained from the corresponding nitrates (Table 1).

The same tendencies persist for cobalt ferrite nanoparticles obtained by hydrothermal synthesis (Fig. 1e,f). However, it should be noted that the average size of crystallites formed in an aqueous medium at elevated pressure and temperature is noticeably lower than that of their analogs obtained in ethylene glycol (Fig. 1c,e). The same can be said about the volume of the unit cell (Table 1).

The value of microstresses for the synthesized $\mathrm{Co}_{x} \mathrm{Fe}_{3-x} \mathrm{O}_{4}$ nanoparticles, regardless of their chemical prehistory and preparation method, was $0.0025 \pm 0.0001(0.25 \pm 0.01 \%)$. 

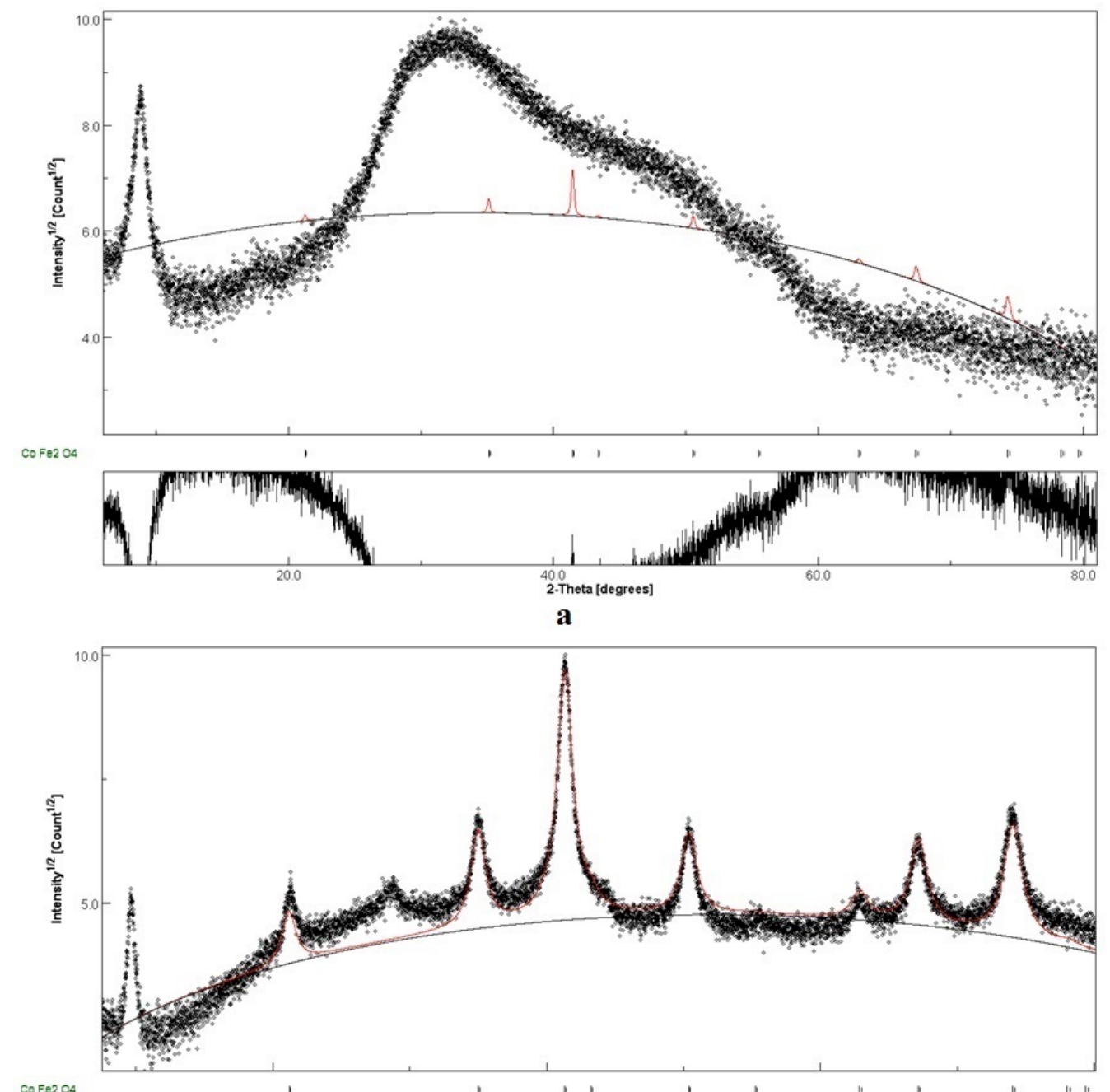

$\mathrm{COFe} 2 \mathrm{OS}$

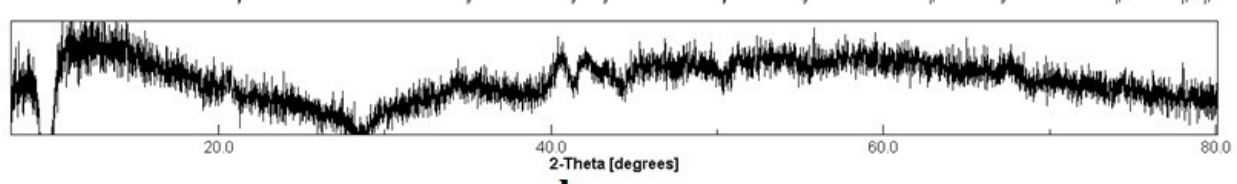

b

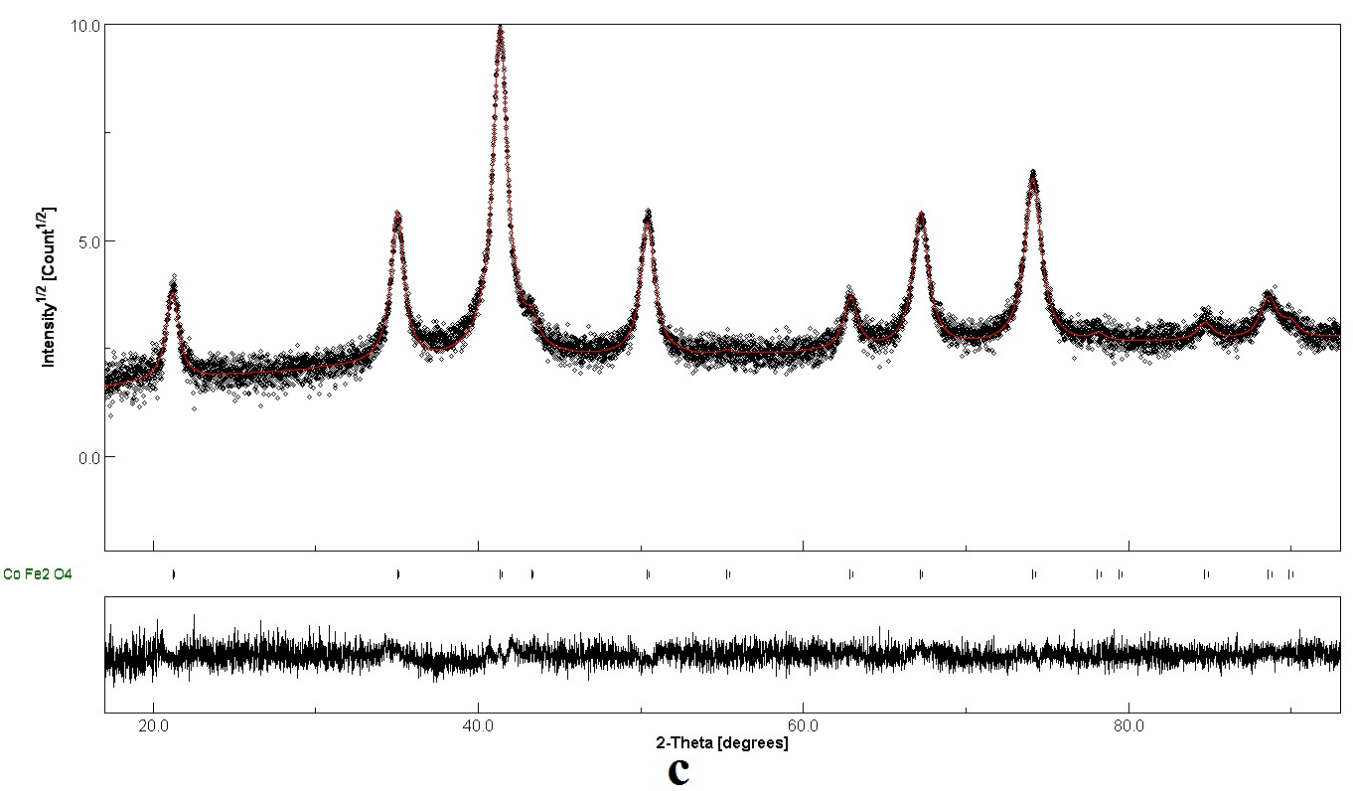



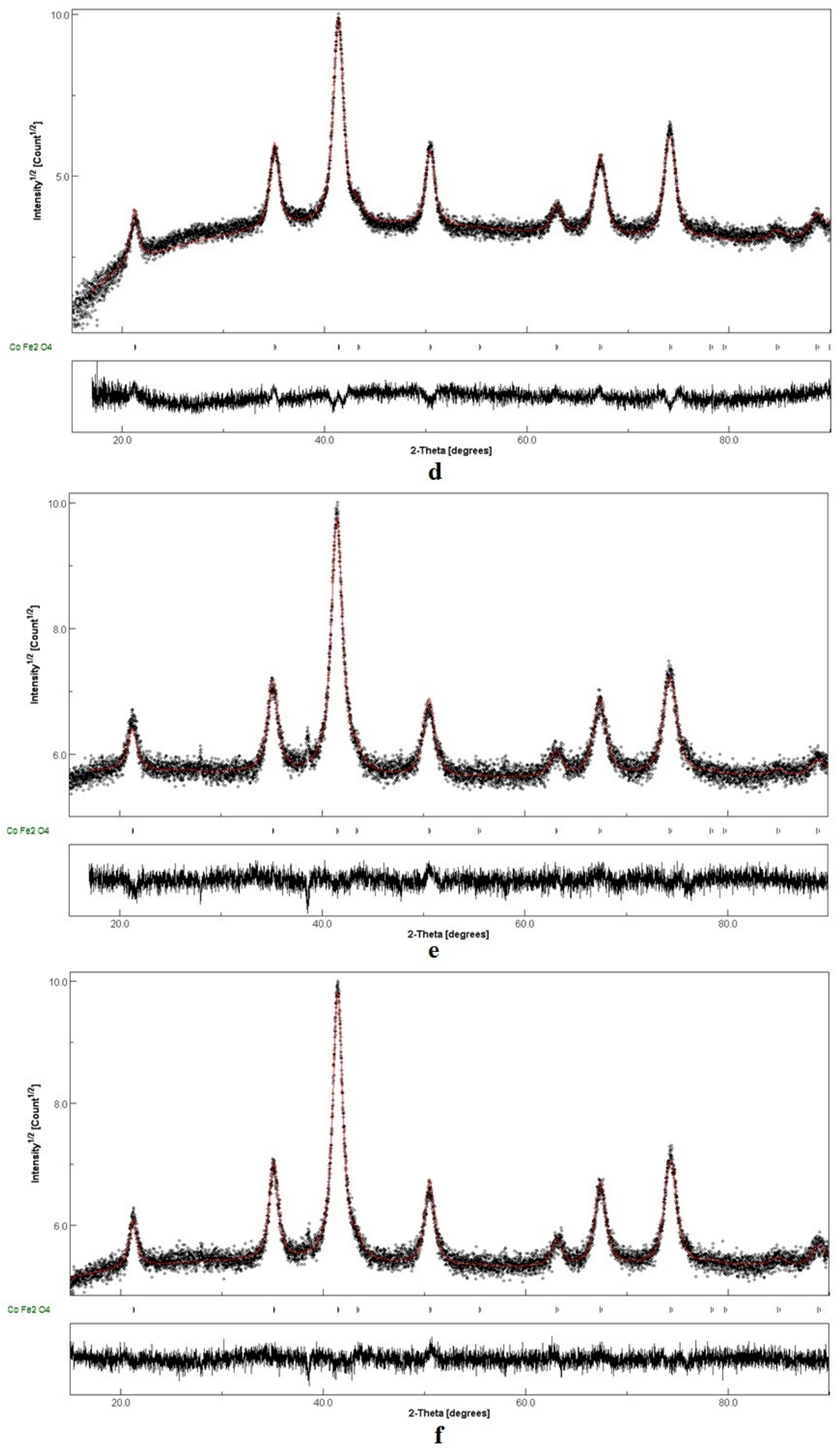

FIG. 1. XRD patterns of SN100 (a), SN150 (b), SN 200 (c), SN2505 (d), HN200 (e), HC200 (f) nanoparticles 
The morphology of $\mathrm{Co}_{x} \mathrm{Fe}_{3-x} \mathrm{O}_{4}$ nanoparticles synthesized by the hydro- and solvothermal method from various precursors is shown in TEM micrographs (Fig. 2a). Cobalt ferrite nanoparticles are mostly quasi-spherical, although a small number of large crystals in the form of plates and octahedra are observed. In Fig. $2 \mathrm{~b}$, the diameter data of quasi-spherical nanoparticles as histograms are statistically treated using a lognormal distribution. Data processing was performed in the program OriginPro 2021b (built 9.8.5.201). The lognormal distribution usually describes the size of the synthesized nanoparticles well. In our case, it is better than the normal one. Besides, the obtained data are shown as Half Violin with data points in the left size (Fig. 2c). The size distribution of nanoparticles turned out to be relatively wide and asymmetric for all the selected synthesis conditions (Fig. 2b,c). It should be noted that the maxima in the size histograms corresponding to the average diameter of nanoparticles, within the limits of the method errors, are comparable to the crystallite sizes determined from the XRD data (Fig. 2b,c, Table 1). Thus, this confirms the earlier conclusion that the formation of smaller $\mathrm{Co}_{x} \mathrm{Fe}_{3-x} \mathrm{O}_{4}$ nanoparticles is facilitated by the hydrolysis of nitrates of the corresponding metals, followed by the dehydration of oxyhydroxides under hydrothermal conditions.

Elemental analysis showed that the content of cobalt in the products of solvothermal synthesis carried out at $100{ }^{\circ} \mathrm{C}$ did not exceed $0.5 \%$ and, therefore, no $\mathrm{Co}_{x} \mathrm{Fe}_{3-x} \mathrm{O}_{4}$ phases were formed (Table 2). This was also confirmed by the XRD data (Fig. 1a). In the case of an increase in the synthesis temperature to $150{ }^{\circ} \mathrm{C}$, a mixed spinel with a stoichiometric coefficient $x=0.535$ was formed. Higher temperatures of isothermal holding of cobalt and iron salts under both hydro and solvothermal conditions increased the degree of substituting $\mathrm{Fe}^{3+}$ ions in octahedral positions by $\mathrm{Co}^{2+}$ but the stoichiometric composition was still not achieved (Table 2).

TABLE 2. Elemental analysis of nanoparticles

\begin{tabular}{|c|c|c|c|c|c|c|}
\hline \multirow{2}{*}{ Sample } & Ratio & \multicolumn{3}{|c|}{ at.\% } & \multicolumn{2}{|c|}{ Stoichiometric ratio $^{1}$} \\
\cline { 2 - 7 } & $\kappa=[\mathrm{Co}] /[\mathrm{Fe}]$ & $\mathrm{Co}$ & $\mathrm{Fe}$ & $\mathrm{O}$ & $x$ & $1-x$ \\
\hline HC200 & 0.401 & 12.18 & 30.4 & 57.42 & 0.858 & 0.142 \\
\hline HN200 & 0.396 & 8.97 & 22.66 & 68.37 & 0.851 & 0.149 \\
\hline SC250 & 0.384 & 10.3 & 26.8 & 62.9 & 0.833 & 0.167 \\
\hline SN250 & 0.357 & 8.31 & 23.26 & 68.43 & 0.790 & 0.210 \\
\hline SN250 & 0.307 & 9.79 & 31.92 & 58.29 & 0.704 & 0.296 \\
\hline SN200 & 0.353 & 9.25 & 26.23 & 64.52 & 0.782 & 0.218 \\
\hline SN150 & 0.217 & 4.24 & 19.54 & 76.22 & 0.535 & 0.465 \\
\hline SN100 & 0.026 & 0.5 & 19.24 & 80.26 & 0.076 & 0.924 \\
\hline
\end{tabular}

${ }^{1}$ The formula for calculating the stoichiometric coefficient:

$\kappa=\frac{x}{3-x} \Leftrightarrow x=\frac{3 \kappa}{1+\kappa} ; \kappa=\frac{[\mathrm{Co}]}{[\mathrm{Fe}]} ; \mathrm{Co}_{x} \mathrm{Fe}_{3-x} \mathrm{O}_{4} \Leftrightarrow\left(\mathrm{CoFe}_{2} \mathrm{O}_{4}\right)_{x}\left(\mathrm{Fe}_{3} \mathrm{O}_{4}\right)_{1-x}$

Studies of the synthesized cobalt ferrite nanoparticles using SQUID magnetometry showed that their magnetization curves have hysteresis loops regardless of the type of precursor used, as well as the chosen conditions of hydrolysis and dehydration (Fig. 3, Table 3). The only exception was $\mathrm{SN} 250^{5}$ for which almost superparamagnetic behavior (low coercive force and zero remanent magnetization) was observed at room temperature (Table 3 ). This may be due to the short synthesis time during which the magnetic domains do not yet have time to form and the magnetic properties of nanoparticles are practically absent [29] (Fig. 3b). It should also be noted that "constricted" hysteresis loops were recorded for cobalt ferrite nanoparticles obtained under hydrothermal conditions or in an organic solvent at temperatures of 150 and $200^{\circ} \mathrm{C}$ (Fig. 3a,c), which are typical for a mixture of soft and hard magnetic materials [1,30]. In this cases, such a "necking" in the central part of the M-H loop can be explained by a small amount of superparamagnetic single-domain particles in ferrimagnetic $\mathrm{Co}_{x} \mathrm{Fe}_{3-x} \mathrm{O}_{4}$ nanocrystals.

The coercive force $\left(\mathrm{H}_{c}\right)$, saturation magnetization $\left(\mathrm{M}_{s}\right)$, remanent magnetization $\left(\mathrm{M}_{r}\right)$ were determined from the M-H curves at 400, 300, and $5 \mathrm{~K}$ for the resulting nanoparticles (Fig. 3, Table 3). The values of $\mathrm{H}_{c}$ and $\mathrm{M}_{s}$ as a function of the average nanoparticle diameter $(D)$ are shown in Fig. 4a,b for a series of crystallites obtained under solvothermal conditions $(S)$ from cobalt and iron nitrates at different temperatures. It was found that the coercive force grew with an increase in the size of the formed $\mathrm{Co}_{x} \mathrm{Fe}_{3-x} \mathrm{O}_{4}$ crystallites. It is known from the literature that, for spherical cobalt ferrite nanoparticles, $\mathrm{H}_{c}$ grows with an increase in their diameter to a specific critical single-domain size, after which the coercivity begins to decrease against the background of further enlargement of crystallites [31]. The maximum $\mathrm{H}_{c}$ is associated with the transition from a magnetic single-domain regime to a multidomain one: from the coherent 


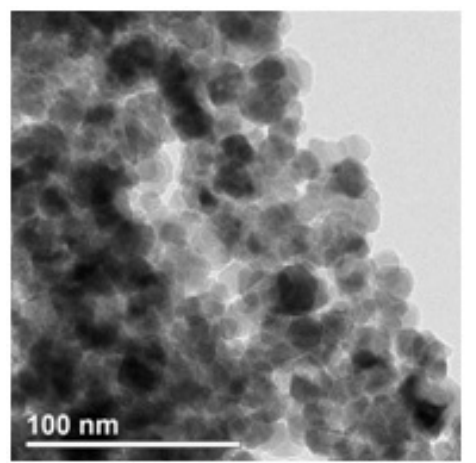

1

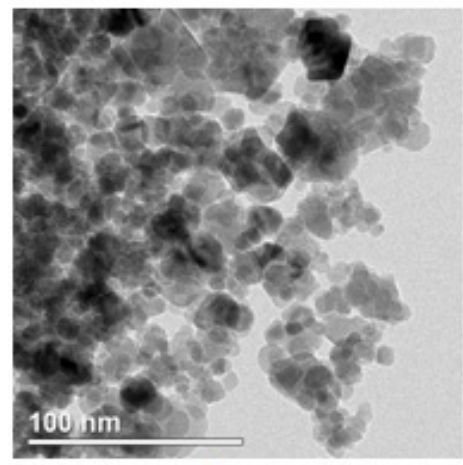

2
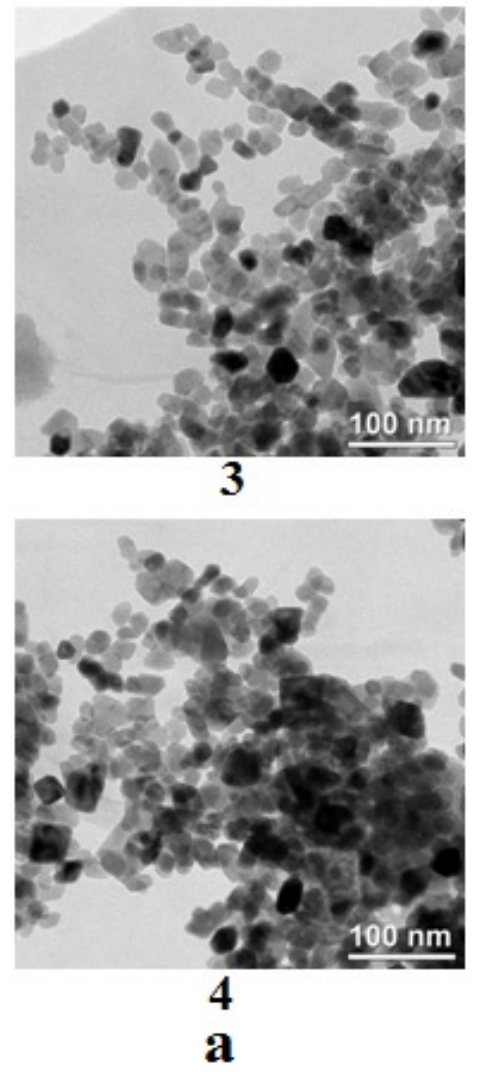
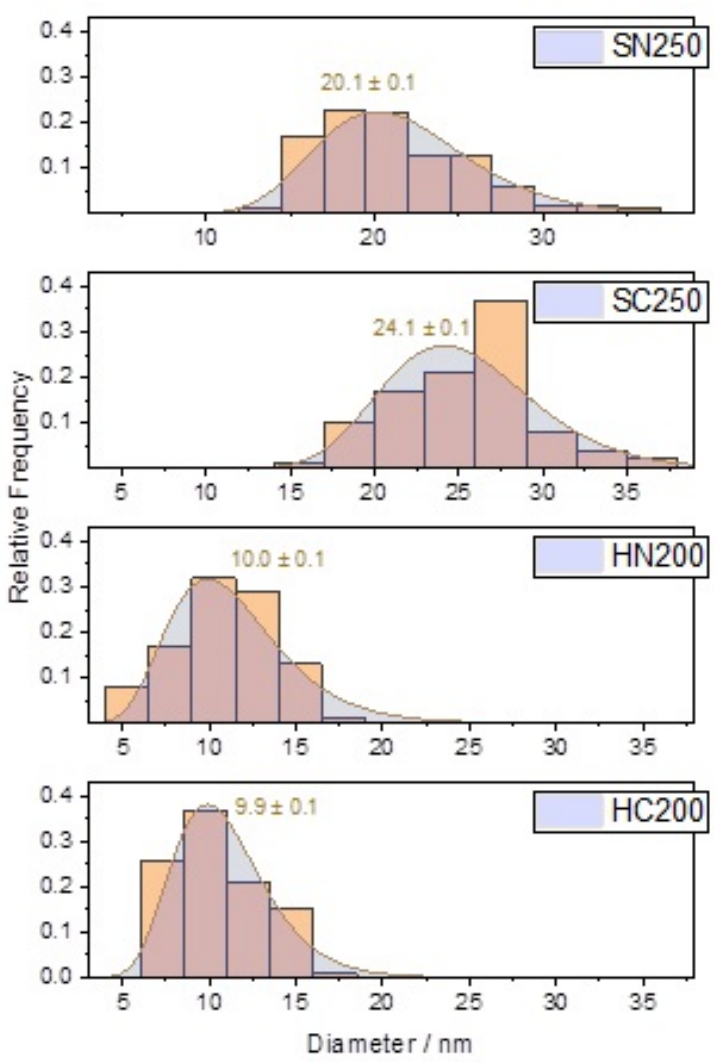

b
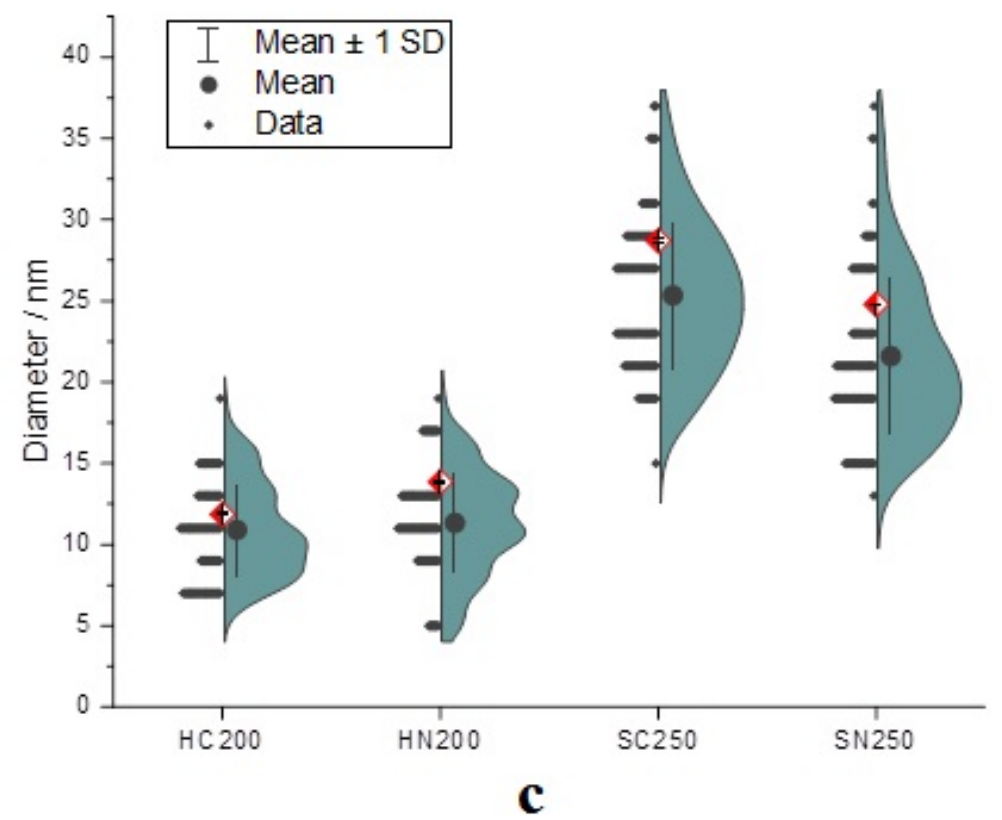

c

FIG. 2. TEM micrographs (a), histograms of size distribution (b) and Half Violin with data points (c) for SN250 ${ }^{10}$ (1), SC250 (2), HN200 (3) and HC200 (4) nanoparticles 


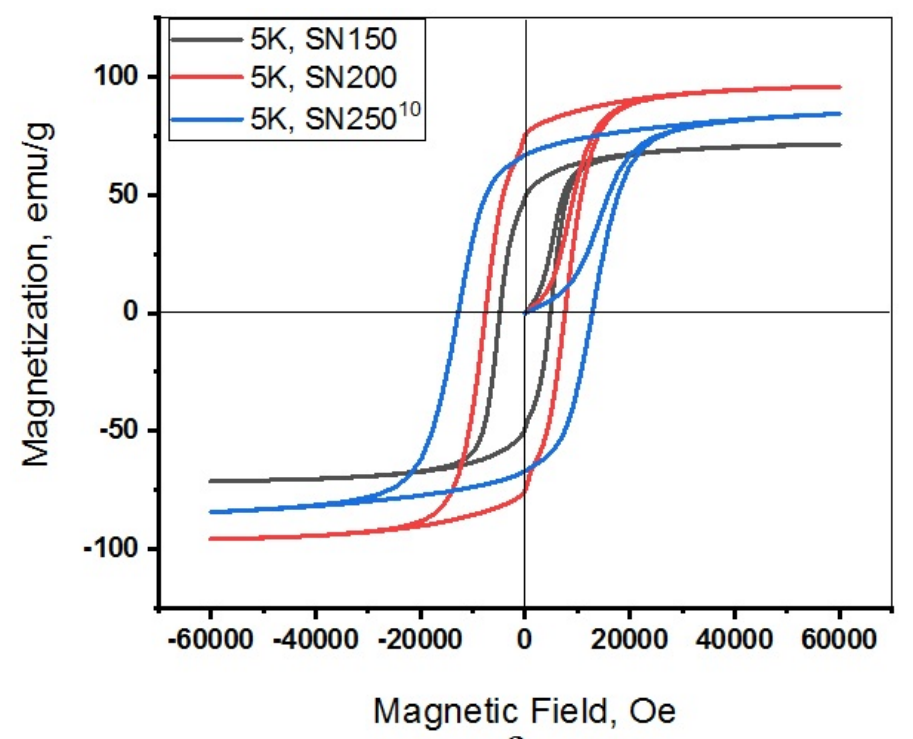

a
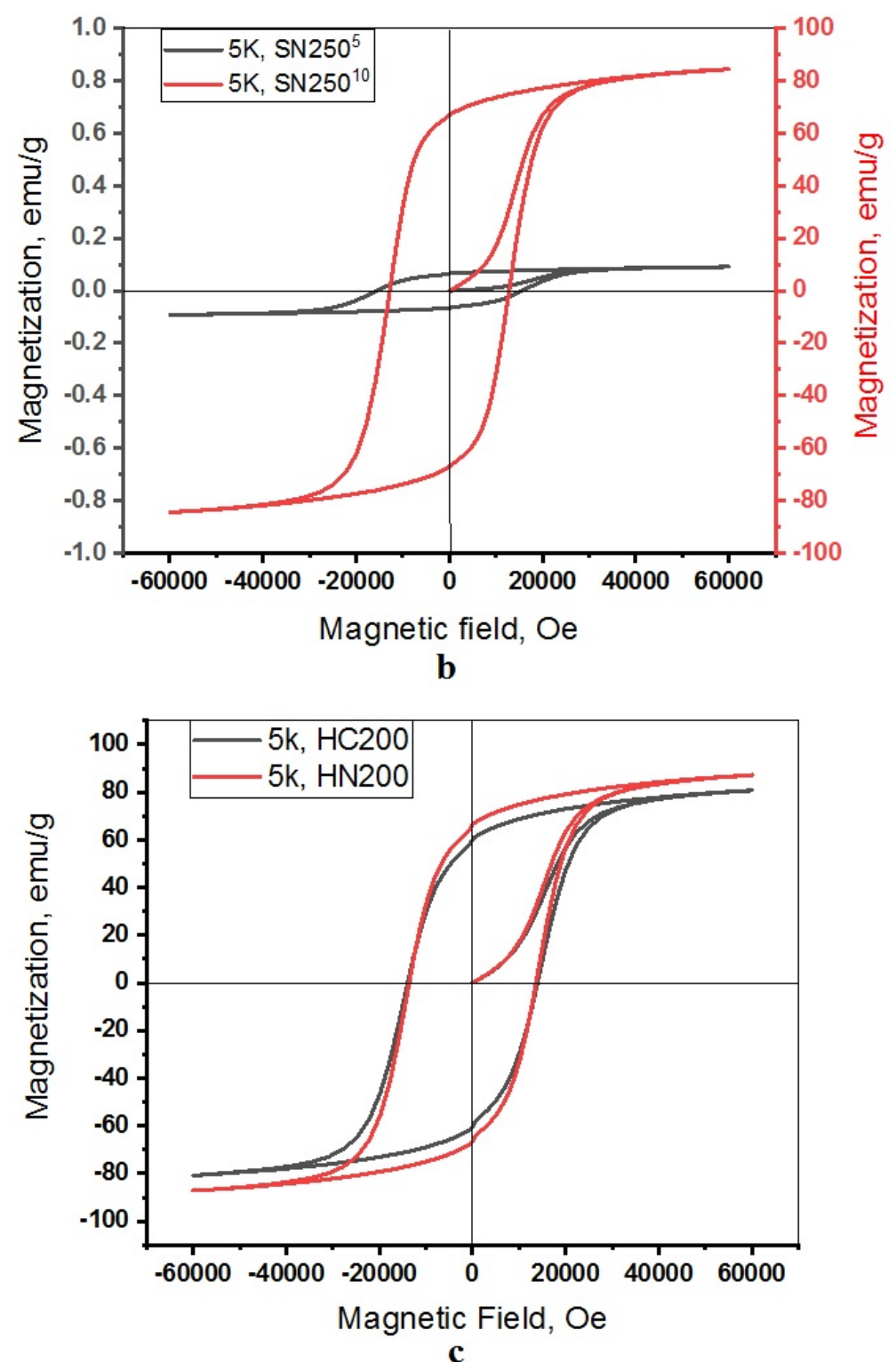

FIG. 3. The low-temperature magnetic hysteresis (M-H) loops for $\mathrm{Co}_{x} \mathrm{Fe}_{3-x} \mathrm{O}_{4}$ nanoparticles synthesized under solvo-(a,b) and hydrothermal conditions (c) 


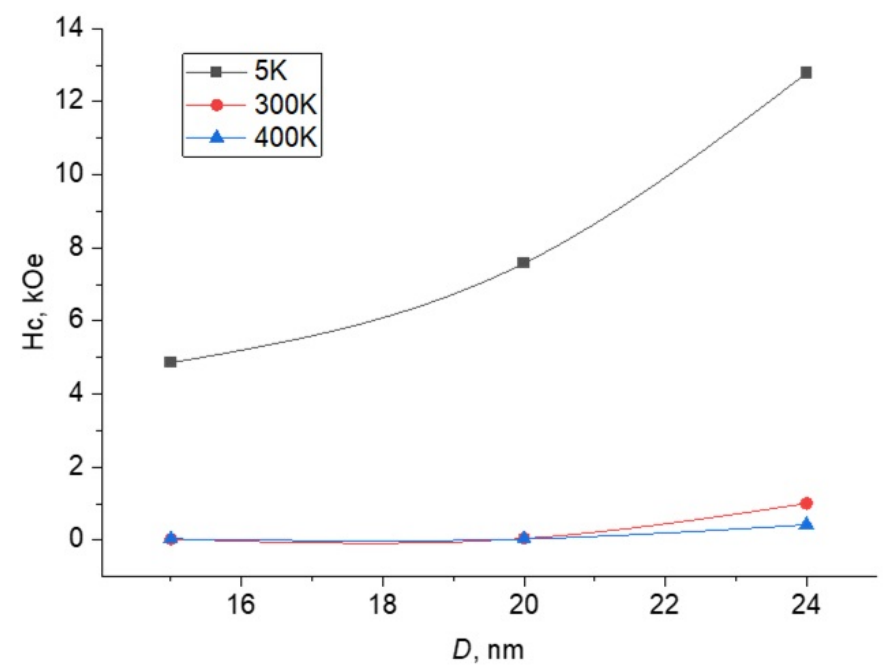

$\mathbf{a}$

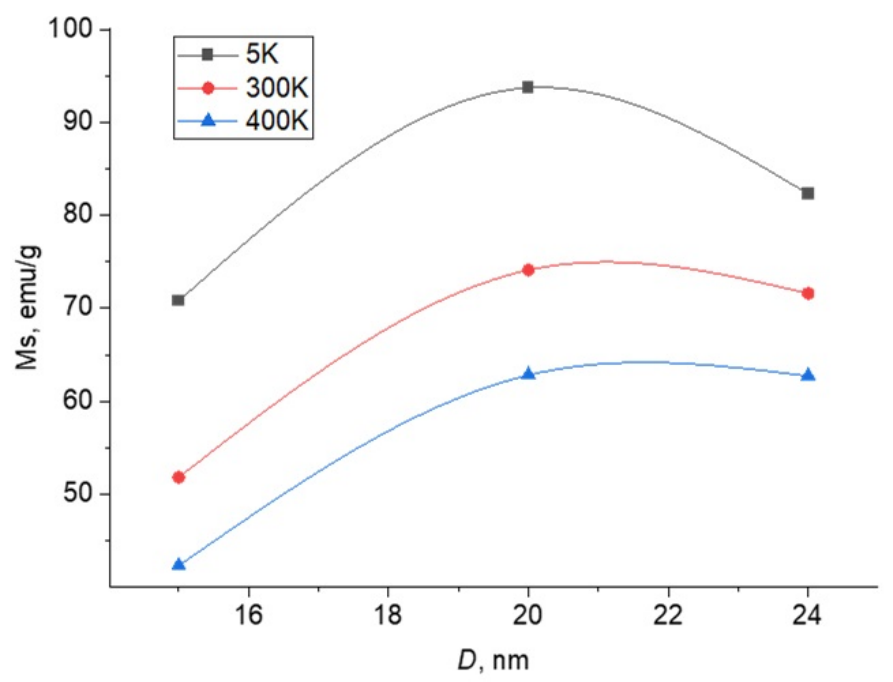

b

FIG. 4. Particle size dependences of (a) coercivity, (b) saturation magnetization for SN150, SN200, and $\mathrm{SN} 250$ samples of $\mathrm{Co}_{x} \mathrm{Fe}_{3-x} \mathrm{O}_{4}$ nanoparticles measured at 5, 300, $400 \mathrm{~K}$

to incoherent rotation of spins (twisting rotation and motion of domain walls) [21]. Since we record an increase in the coercivity in the size range from 10 to $24 \mathrm{~nm}$ and do not reach the maximum, we assume that all nanoparticles obtained in the $\mathrm{S}$ series are single-domain. The saturation magnetization plotted as a function of size at 400, 300, and $5 \mathrm{~K}$ shows its initial increase with growing $D$, but above a specific size, it tends to be a kind of plateau with values comparable to those of bulk $\mathrm{CoFe}_{2} \mathrm{O}_{4}$ (Fig. 4b) [16]. The increase in $\mathrm{M}_{s}$ with diameter for single-domain particles can be understood by considering the core-shell model [16,31,32]. An oriented magnetic domain is considered as a core, and disordered spins on the surface due to imperfect coordination of surface atoms create a shell, the so-called surface "dead magnetic layer" [21]. As the particle size increases, the ratio of the shell thickness to the volume of the domain (core) decreases, which leads to an increase in $\mathbf{M}_{s}$. When particles approach the multidomain state, the growth of the magnetization values stops.

Low remanent magnetization and almost zero squareness at room temperature for SN150 and SN200 nanoparticles may mean their superparamagnetic behavior is replaced by ferrimagnetic behavior with an increase in the synthesis temperature to $250{ }^{\circ} \mathrm{C}$. According to the Stoner-Wohlfarth model, the fixed $\mathrm{M}_{r} / \mathrm{M}_{s}$ values for synthesized singledomain particles are within the range of values characteristic of non-interacting three-dimensional random particles 

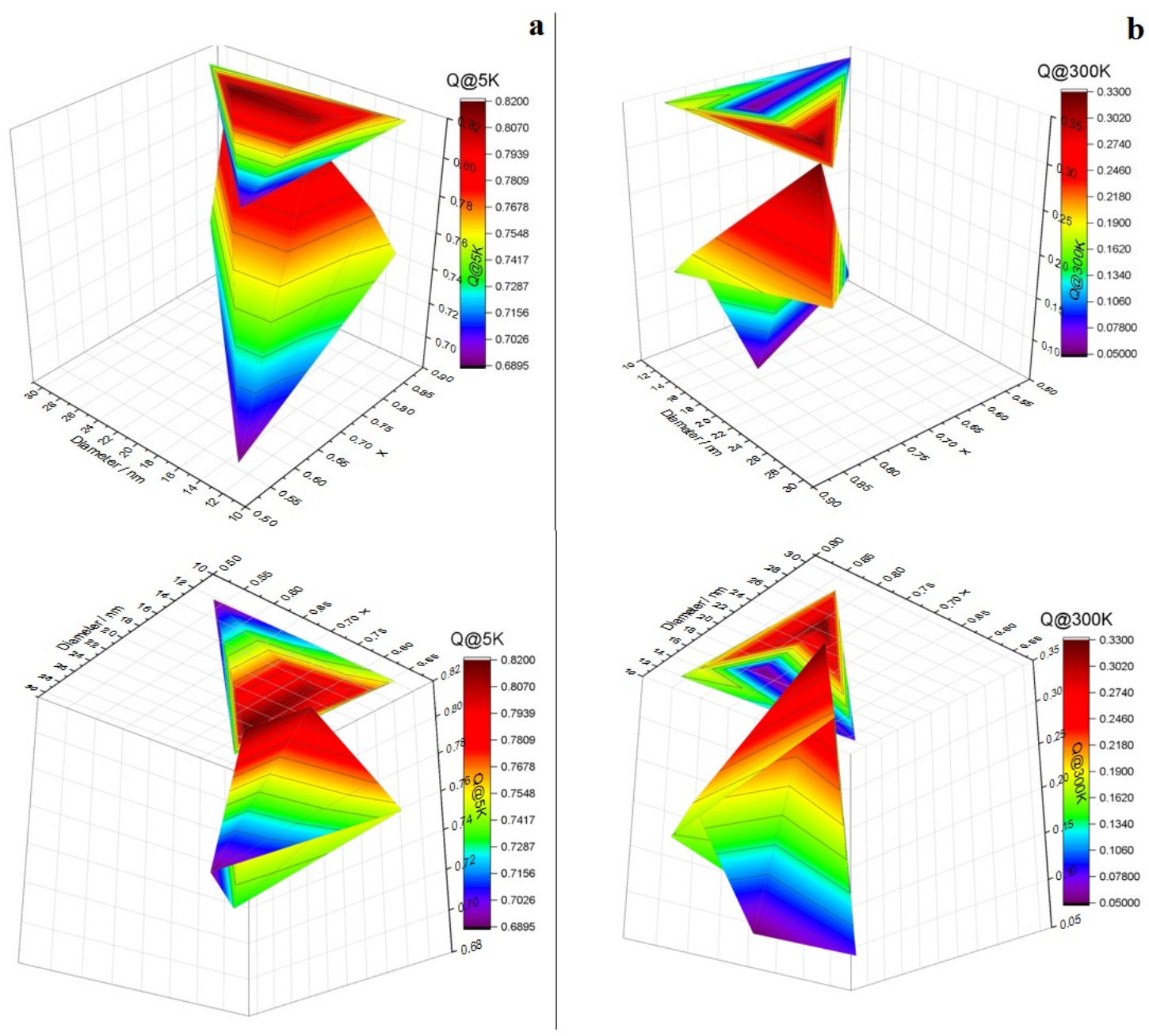

FIG. 5. Dependence of the magnetization hysteresis loop squareness on the stoichiometry of the elemental composition and nanoparticle size at 5 (a) and $300 \mathrm{~K}$ (b)

with uniaxial anisotropy [26]. Only samples SN250 and SC250 are knocked out of the available row. The $\mathbf{M}_{r}$ and $\mathrm{M}_{r} / \mathrm{M}_{s}$ values measured at $5 \mathrm{~K}$ turned out to be larger than the values estimated at 300 and $400 \mathrm{~K}$. For this, a possible reason may be associated with the increased ratio of magnetic anisotropy to thermal energy at low temperatures [21].

Figure 5 shows surfaces of the squareness $(Q)$ dependence of the hysteresis loops for the magnetization of synthesized cobalt ferrite nanoparticles (Table 3 ) on their stoichiometry and size:

$$
Q=\frac{M_{r}}{M_{s}}=f(x, D)
$$

where $M_{r}$ is the remanent magnetization, $M_{s}$ is the saturation magnetization, $x$ is the stoichiometric coefficient of the composition of $\mathrm{Co}_{x} \mathrm{Fe}_{(3-x)} \mathrm{O}_{4}$ nanoparticles (Table 2), $D$ is the size of $\mathrm{Co}_{x} \mathrm{Fe}_{(3-x)} \mathrm{O}_{4}$ nanoparticles obtained from TEM data.

Part of Fig. 5, corresponding to the coordinate plane $(x, D)$, shows the projection of the two-dimensional surface of the quantity $Q$ in the form of a color map. It was determined that the maximum squareness of 0.82 at $5 \mathrm{~K}$ of the hysteresis loop is at a composition stoichiometry $x$ of about $0.77-0.80$ and a particle diameter in the range of $16-$ $25 \mathrm{~nm}$. At $300 \mathrm{~K}$, the maximum $Q$ value of about 0.33 is observed at the same $x$ and a nanoparticle size of $25 \mathrm{~nm}$.

The analysis of the magnetic properties of $\mathrm{Co}_{x} \mathrm{Fe}_{3-x} \mathrm{O}_{4}$ nanoparticles obtained under hydro or solvothermal conditions, depending on the nature of the anion of the salt used, concludes that there is no noticeable difference between them at low temperatures. At $300 \mathrm{~K}$ and higher, for nanoparticles obtained from Co and Fe nitrates, the values of $H_{c}, M_{r}$ are higher than those for their analogs SC250 and HC200.

The magnetic parameters strongly depend on the distribution of cations $\left(\mathrm{Co}^{2+}, \mathrm{Fe}^{2+}, \mathrm{Fe}^{3+}\right)$ between the tetrahedral and octahedral positions. $\mathrm{Fe}^{3+}$ and $\mathrm{Co}^{2+}$ ions can occupy tetrahedral vacancies (A-positions) or octahedral 

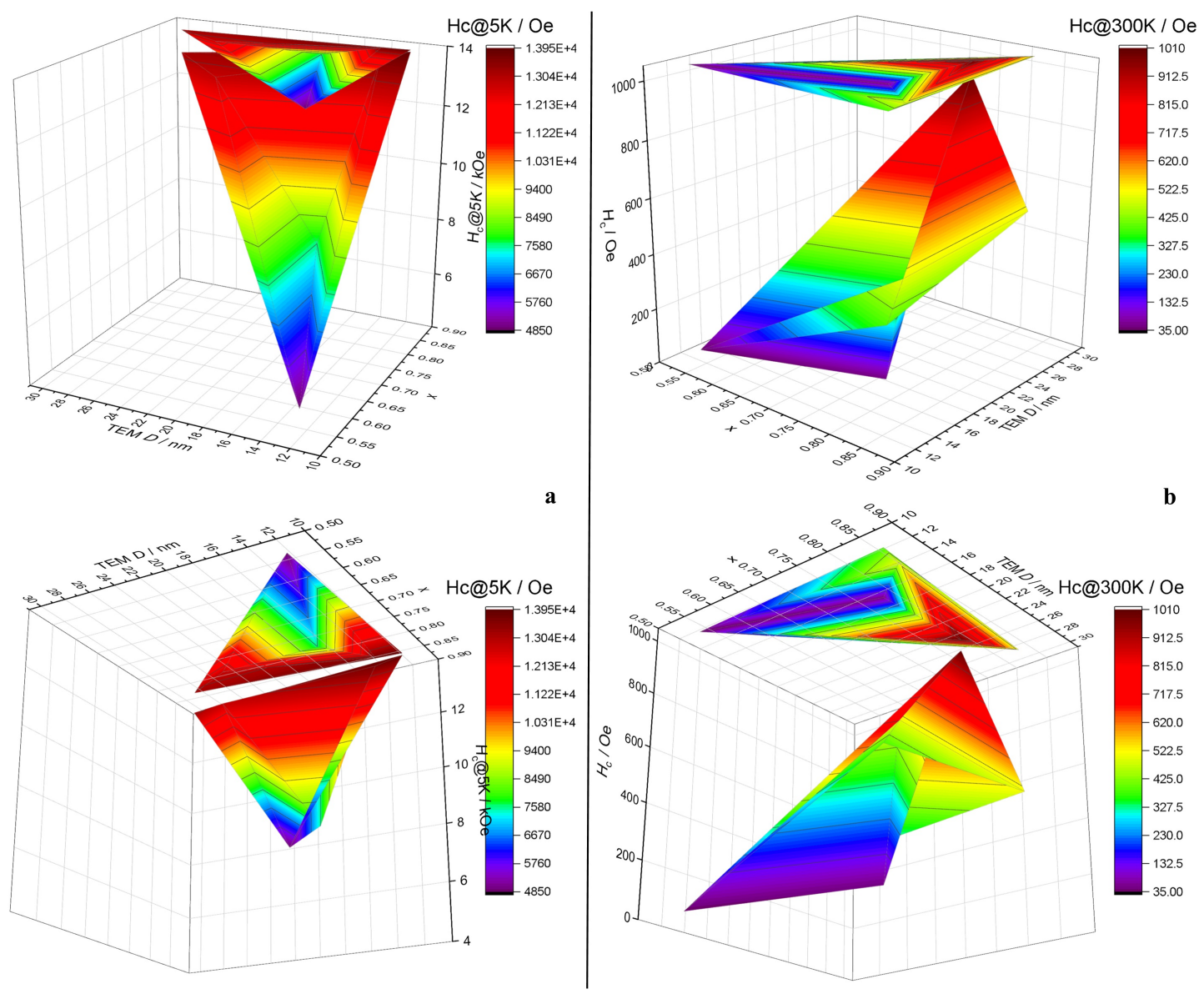

FIG. 6. Dependence of the coercive force on the stoichiometry of the elemental composition and size of cobalt ferrite nanoparticles at 5 (a) and $300 \mathrm{~K}$ (b)

TABLE 3. Magnetic characteristics of $\mathrm{Co}_{x} \mathrm{Fe}_{3-x} \mathrm{O}_{4}$ nanoparticles depending on their chemical and thermal prehistory

\begin{tabular}{|c|c|c|c|c|c|c|c|c|c|c|c|c|}
\hline \multirow{3}{*}{ Sample } & \multicolumn{12}{|c|}{ Temperature } \\
\hline & \multicolumn{4}{|c|}{$5 \mathrm{~K}$} & \multicolumn{4}{|c|}{$300 \mathrm{~K}$} & \multicolumn{4}{|c|}{$400 \mathrm{~K}$} \\
\hline & $Q^{1)}$ & $\begin{array}{c}M_{r}, \\
\mathrm{emu} / \mathrm{g}\end{array}$ & $\begin{array}{c}M_{s}, \\
\mathrm{emu} / \mathrm{g}\end{array}$ & $\begin{array}{c}H_{c} \\
\text { Oe }\end{array}$ & $Q$ & $\begin{array}{c}M_{r} \\
\mathrm{emu} / \mathrm{g}\end{array}$ & $\begin{array}{c}M_{s}, \\
\mathrm{emu} / \mathrm{g}\end{array}$ & $\begin{array}{c}H_{c} \\
\text { Oe }\end{array}$ & $Q$ & $\begin{array}{c}M_{r}, \\
\mathrm{emu} / \mathrm{g}\end{array}$ & $\begin{array}{c}M_{s}, \\
\mathrm{emu} / \mathrm{g}\end{array}$ & $\begin{array}{c}H_{c}, \\
\text { Oe }\end{array}$ \\
\hline HC200 & 0.75 & 60.2 & 80.8 & 13935 & 0.16 & 11 & 68.2 & 385 & 0.04 & 2.2 & 58.6 & 46 \\
\hline HN200 & 0.77 & 66.7 & 87.2 & 13657 & 0.19 & 13.8 & 72.7 & 499 & 0.06 & 3.6 & 61.4 & 86 \\
\hline SC250 & 0.73 & 69.5 & 95 & 13210 & 0.21 & 16.8 & 79.9 & 504 & 0.04 & 3.1 & 70.4 & 56 \\
\hline $\mathrm{SN} 250^{10}$ & 0.82 & 67.1 & 82.3 & 12783 & 0.33 & 23.9 & 71.6 & 1007 & 0.21 & 12.9 & 62.7 & 421 \\
\hline SN250 & - & 0.07 & 0.09 & 15635 & - & 0.01 & 0.08 & 276 & - & - & 0.06 & - \\
\hline SN200 & 0.81 & 75.7 & 93.7 & 7583 & 0.05 & 4 & 74.1 & 47 & 0.07 & 4.5 & 62.8 & 33 \\
\hline SN150 & 0.69 & 49.1 & 70.8 & 4856 & 0.08 & 4.1 & 51.8 & 35 & 0.08 & 3.3 & 42.3 & 36 \\
\hline
\end{tabular}

${ }^{1}$ squareness of magnetization hysteresis loops for $\mathrm{Co}_{x} \mathrm{Fe}_{3-x} \mathrm{O}_{4}$ nanoparticles: $Q=\frac{M_{r}}{M_{s}}$ 
interstices (B-positions) in a cation-substituted spinel $\left(\mathrm{Co}_{z}^{2+} \mathrm{Fe}_{1-z}^{3+}\right)^{A}\left[\mathrm{Fe}_{1+z}^{3+} \mathrm{Co}_{1-z}^{2+}\right]^{B} \mathrm{O}_{4}$, where $z$ is the extrinsic site inversion $[3,33]$. The change of the magnetization in the ferrimagnetic spinel can be explained by the antiparallel interaction between the moments of the cations in the $\mathrm{A}$ and $\mathrm{B}$ positions. The magnetic moment of the $\mathrm{Co}^{2+}$ ion $(3 \mu \mathrm{B})$ is less than that of the $\mathrm{Fe}^{2+}(4 \mu \mathrm{B})$ and $\mathrm{Fe}^{3+}(5 \mu \mathrm{B})$ ions. At low degrees of inversion, $\mathrm{Co}^{2+}$ ions prefer to substitute for $\mathrm{Fe}^{3+}$ ions in the A-sites, which decreases the magnetic moment of the tetragonal regions and increases the total magnetic moment. The exchange interaction $\mathrm{A}-\mathrm{O}-\mathrm{B}$ remains stronger than $\mathrm{A}-\mathrm{O}-\mathrm{A}$ and $\mathrm{B}-\mathrm{O}-\mathrm{B}$. However, the exchange interactions $\mathrm{A}-\mathrm{O}-\mathrm{B}$ weaken with an increase in the degree of substitution of $\mathrm{Fe}^{3+}$ ions on $\mathrm{Co}^{2+}$ in the A-sites. Because of the latter, the magnetic moments of the tetrahedral and octahedral positions align antiparallel to each other.

The increase in the coercive force seen in Fig. 6a is associated at $5 \mathrm{~K}$ with an increase in the stoichiometric ratio. The $H_{c}$ extremum of $13-15 \mathrm{kOe}$ is observed at $x$ in the range of $0.82-0.85$, while the particle diameter varies over a wide range of $12-28 \mathrm{~nm}$. However, at $300 \mathrm{~K}$, an $H_{c}$ maximum is equal to $\mathrm{ca}$. $1 \mathrm{kOe}$, observed at 0.79 for nanoparticles with a diameter of $25 \mathrm{~nm}$ (Fig. 6b), which agrees with the literature data [10,14].

\section{Conclusions}

The synthesis of cobalt ferrite, an essential step towards creating new efficient ferrimagnetic nanoparticles, requires control over many physicochemical parameters. When synthesizing cobalt ferrite nanoparticles by the solvo(hydro)thermal method, varying the temperature, nature of the solvent, and counterions for cobalt(II) and iron(III) makes it possible to create $\mathrm{Co}_{x} \mathrm{Fe}_{3-x} \mathrm{O}_{4}$ nanoparticles with different stoichiometric ratios. Analysis of the data obtained allowed us to conclude that changes in the conditions for the synthesis of particles from $\mathrm{Fe}^{3+}$ and $\mathrm{Co}^{2+}$ lead to significant changes in the nanoparticles' properties. These properties include the contribution of the superparamagnetic fraction, the degree of spinel inversion, the average size of nanoparticles, coercivity, and saturation magnetization. The results obtained can be used to develop scientific recommendations for developing state-of-the-art materials for medical applications and in engineering. Further research is needed to understand the relationship between the solvo(hydro)thermal synthesis conditions, the structure of the nanoparticles formed, and their functional (magnetic) properties.

\section{Acknowledgement}

X-ray diffraction experiments were performed on the Engineering Center equipment of the St. Petersburg State Technological Institute (Technical University). TEM studies were carried out in the Federal Joint Research Center "Material science and characterization in advanced technology" funded by the Ministry of Education and Science of the Russian Federation.

\section{References}

[1] Perales-Pérez O., Cedeño-Mattei Y. Optimizing processing conditions to produce cobalt ferrite nanoparticles of desired size and magnetic. Magnetic Spinels - Synthesis, Properties and Applications, Mohindar Singh Seehra, IntechOpen, 2017.

[2] López-Ortega A. Lottini E., Fernandez C.D.J., Sangregorio C. Exploring the magnetic properties of cobalt ferrite nanoparticles for the development of a rare-earth-free permanent magnet. Chem. Mater., 2015, 27, P. 4048-4056.

[3] Kumar P., Pathak S., Singh A., Kuldeep, Khanduri H., Wang X., Basheed G.A., Pant R.P. Optimization of cobalt concentration for improved magnetic characteristics and stability of $\mathrm{Co}_{x} \mathrm{Fe}_{3-x} \mathrm{O}_{4}$ mixed ferrite nanomagnetic fluids. Mater. Chem. Phys., 2021, 265, P. 124476.

[4] Goh S.C., Chia C.H., Zakaria S., Yusoff M., Haw C.Y., Ahmadi Sh., Huang N.M., Lim H.N. Hydrothermal preparation of high saturation magnetization and coercivity cobalt ferrite nano crystals without subsequent calcinations. Mater. Chem. Phys., 2010, 120, P. 31-35.

[5] Labchir N., Hannour A., Aithssi A., Vincent D., Ganster P., Ihlal A. Controlled electrochemical growth and magnetic properties of CoFe ${ }_{2} \mathrm{O}_{4}$ nanowires with high internal magnetic field. J. Alloys Compd., 2021, 868, P. 159196.

[6] Suginoto M. The past, present, and future of ferrites. J. Am. Ceram. Soc., 1999, 82, P. 269.

[7] Karthick R., Ramachandran K., Srinivasan R. Study of Faraday effect on $\mathrm{Co}_{1-x} \mathrm{Zn}_{x} \mathrm{Fe}_{2} \mathrm{O}_{4}$ nanoferrofluids. Nanosystems: Physics, Chemistry, Mathematics, 2016, 7(4), P. 624-628.

[8] Manohar A., Geleta D.D., Krishnamoorthi C., Lee J. Synthesis, characterization and magnetic hyperthermia properties of nearly monodisperse $\mathrm{CoFe}_{2} \mathrm{O}_{4}$ nanoparticles. Ceramics International, 2020, 46(18), P. 28035-28041.

[9] Javed F., Abbas M.A., Asad M.I., Ahmed N., Naseer N., Saleem H., Errachid A., Lebaz N., Elaissari A., Ahmad N.M. Gd ${ }^{3+}$ doped CoFe 2 O 4 nanoparticles for targeted drug delivery and magnetic resonance imaging. Magnetochemistry, 2021, 7, P. 47.

[10] Li Y., Lu X., Yang S., Duan W., Zhang Y., Zhou C., Li K., Zhang Y., Shi Q. Synthesis of monodisperse ferromagnetic Co ${ }_{x} F_{3-x} \mathrm{O}_{4}$ colloidal particles with magnetically tunable optical properties. CrystEngComm, 2019.

[11] Shirsath S.E., Liu X., Yasukawa Y., Li S., Morisako A. Switching of magnetic easy-axis using crystal orientation for large perpendicular coercivity in $\mathrm{CoFe}_{2} \mathrm{O}_{4}$ thin film. Scientific Reports, 2016,6, P. 30074.

[12] Long N.V., Yang Y., Teranishi T., Thi C.M., Cao Y., Nogami M. Related magnetic properties of $\mathrm{CoFe}_{2} \mathrm{O}_{4}$ cobalt ferrite particles synthesised by the polyol method with $\mathrm{NaBH}_{4}$ and heat treatment: new micro and nanoscale structures. RSC Adv., 2015, 5, P. 56560-56569.

[13] Yasemian A.R., Kashi M.A., Ramazani A. Exploring the effect of Co concentration on magnetic hyperthermia properties of $\mathrm{Co}_{x} \mathrm{Fe}_{3-x} \mathrm{O}_{4}$ nanoparticles. Mater. Res. Express, 2020, 7, P. 016113.

[14] Dehsari H.S., Asadi K. The impact of stoichiometry and size on magnetic properties of cobalt-ferrite nanoparticles. J. Phys. Chem. C, 2018. 
[15] Gandha K., Elkins K., Poudyal N., Liu J.P. Synthesis and characterization of $\mathrm{CoFe}_{2} \mathrm{O}_{4}$ nanoparticles with high coercivity. Journal of Applied Physics, 2015, 117, P. 17A736.

[16] Artus M., Tahar L.B., Herbst F., Smiri L., Villain F., Yaacoub N., Gren'eche J.-M., Ammar S., Fi'evet F. Size-dependent magnetic properties of $\mathrm{CoFe}_{2} \mathrm{O}_{4}$ nanoparticles prepared in polyol. J. Phys.: Condens. Matter., 2011, 23, P. 506001.

[17] Liu C., Rondinone A.J., Zhang Z.J.Synthesis of magnetic spinel ferrite $\mathrm{CoFe}_{2} \mathrm{O}_{4}$ nanoparticles from ferric salt and characterization of the size-dependent superparamagnetic properties. Pure Appl. Chem. 2000, 72(1,2), P. 37.

[18] Song Q., Zhang Z.J. Correlation between spin-orbital coupling and the superparamagnetic properties in magnetite and cobalt ferrite spinel nanocrystals. J. Phys. Chem. B, 2006, 110, P. 11205-11209.

[19] Maaz K., Mumtaz A., Hasanain S.K., Ceylan A Synthesis and magnetic properties of cobalt ferrite $\left(\mathrm{CoFe}_{2} \mathrm{O}_{4}\right)$ nanoparticles prepared by wet chemical route. J. Magn. Magn. Mater, 2007, 30(8), P. 289-295.

[20] Shyamaldas, Bououdina M., Manoharan C. Dependence of structure/morphology on electrical/magnetic properties of hydrothermally synthesised cobalt ferrite nanoparticles. Journal of Magnetism and Magnetic Materials, 2020, 493, P. 165703.

[21] Das A., Bestha K.K., Bongurala P., Gorige V. Correlation between size, shape and magnetic anisotropy of CoFe ${ }_{2} \mathrm{O}_{4}$ ferrite nanoparticles. Nanotechnology, 2020, 31, P. 335716.

[22] Kumar Y., Sharma A., Ahmed Md.A., Mali S.S., Hong C.K., Shirage P.M. Morphology-controlled synthesis and enhanced energy product $(\mathrm{BH}) \mathrm{max}$ of $\mathrm{CoFe}_{2} \mathrm{O}_{4}$ nanoparticles.

[23] Fayazzadeh S., Khodaei M., Arani M., Mahdavi S.R., Nizamov T., Majouga A. Magnetic properties and magnetic hyperthermia of cobalt ferrite nanoparticles synthesized by hydrothermal method. Journal of Superconductivity and Novel Magnetism, 2020,3(3), P. $2227-2233$.

[24] Almjasheva O.V., Gusarov V.V. Prenucleation formations in control over synthesis of $\mathrm{CoFe}_{2} \mathrm{O}_{4}$ nanocrystalline powders. Russian Journal of Applied Chemistry, 2016, 89(6), P. 851-856.

[25] Dippong T., Levei E.A., Cadar O. Recent advances in synthesis and applications of $\mathrm{MFe}_{2} \mathrm{O}_{4}(\mathrm{M}=\mathrm{Co}, \mathrm{Cu}, \mathrm{Mn}, \mathrm{Ni}, \mathrm{Zn}) \mathrm{nanoparticles}$. Nanomaterials, 2021, 11, P. 1560.

[26] Kuznetsova V., Almjasheva O., Gusarov V.V. Influence of microwave and ultrasonic treatment on the formation of $\mathrm{CoFe}_{2} \mathrm{O}_{4}$ under hydrothermal conditions. Glass Physics and Chemistry, 2009, 35(2), P. 205-209.

[27] Lutterotti L., Bortolotti M., Ischia G., Lonardelli I., Wenk H.-R. Rietveld texture analysis from diffraction images. Z. Kristallogr., Suppl., 2007, 26, P. 125-130.

[28] Barashok K.I., Panchuk V.V., Semenov V.G., Almjasheva O.V., Abiev R.Sh. Formation of cobalt ferrite nanopowders in an impinging-jets microreactor. Nanosystems: Physics, Chemistry, Mathematics, 2021, 12(3), P. 30-310.

[29] Yuan Y., Wei S., Liang Y., Wang B., Wang Y. Effect of solvothermal reaction-time on microstructure and microwave absorption properties of cobalt ferrite. Materials, 2020, 13, P. 5331.

[30] Zhao L., Zhang H., Xing Y., Song S., Yu S., Shi W., Guo X., Yang J., Lei Y., Cao F. Studies on the magnetism of cobalt ferrite nanocrystals synthesized by hydrothermal method. J. Solid State Chem., 2008, 181, P. 245-252.

[31] Lu R.E., Chang K. G., Fu B., Shen Y.J., Xu M.W., Yang S., Song X.P., Liu M., Yang Y.D. Magnetic properties of different CoFe ${ }_{2}$ O $_{4}$ nanostructures: nanofibers versus nanoparticles. J. Mater. Chem. C, 2014, 2, P. 8578.

[32] Ansari S.M., Sinha B.B., Phase D., Sen D., Sastry P.U., Kolekar Y.D., Ramana C.V. Particle size, morphology, and chemical composition controlled $\mathrm{CoFe}_{2} \mathrm{O}_{4}$ nanoparticles with tunable magnetic properties via oleic acid based solvothermal synthesis for application in electronic devices. ACS Appl. Nano Mater., 2019, 2, P. 182-1843.

[33] Raghvendra Yadav S., Havlica J., Masilko J., Kalina L., Hajdúchová M., Enev V., Wasserbauer J., Kuřitka I., Kozakova Z. Structural, cation distribution, and magnetic properties of $\mathrm{CoFe}_{2} \mathrm{O}_{4}$ spinel ferrite nanoparticles synthesized using a starch-assisted sol-gel auto-combustion method. Journal of Superconductivity and Novel Magnetism, 2015, 28, P. 1851-1861. 